\title{
RANCANG BANGUN WEB REPOSITORI SKRIPSI MAHASISWA BERBASIS OAI-PMH 2.0 MENGGUNAKAN GOOGLE APP ENGINE (STUDI KASUS : PROGRAM STUDI ILMU KOMPUTER UNIVERSITAS MULAWARMAN)
}

\author{
Pebrida Saputri $^{1)}$, Zainal Arifin ${ }^{2)}$, Yulianto ${ }^{3)}$ \\ 1,2,3) Jurusan Ilmu Komputer FMIPA Universitas Mulawarman \\ Jalan Barong Tongkok No. 4 Kampus Gunung Kelua Samarinda, Kalimantan Timur \\ Email : pebrida.saputri@gmail.com ${ }^{1)}$, zainal.ilkom.unmul@gmail.com ${ }^{2)}$, yulianto.tile @yahoo.com ${ }^{3)}$
}

\begin{abstract}
ABSTRAK
Repositori umumnya merupakan tempat penyimpanan yang bersifat online untuk mengumpulkan, mengelola, menyebarkan dan melestarikan karya-karya ilmiah yang dihasilkan atau output dari civitas akademik sebuah perguruan tinggi. Dalam lingkup civitas perguruan tinggi repositori sendiri dikenal dengan repositori institusi yang berhubungan erat dengan digital library. Universitas Mulawarman, sejauh ini belum mempunyai wadah untuk menampung semua kumpulan karya ilmiah termasuk dalam hal ini tugas akhir atau skripsi secara online, melainkan hanya dalam bentuk buku yang di kumpulkan di perpustakaan dari fakultas masing-masing. Untuk memudahkan terjadinya pertukaran informasi hasil-hasil karya ilmiah yang telah dihasilkan dibutuhkan suatu sistem harvesting yang terhubung dalam jaringan repositori digital. Sistem harvesting yang akan diimplementasikan adalah sebuah harvester yang menggunakan standar Open Archives Initiative Protocol for Metadata Harvesting (OAI-PMH), yang merupakan teknologi yang bisa digunakan dan diimplementasikan untuk melakukan standarisasi metadata dari koleksi digital. OAI-PMH digunakan untuk membantu dalam proses penyebaran dan akses metadata yang terdapat didalam web repositori tersebut yang berjalan diatas Google App Engine dan berguna untuk memudahkan availibilitas terhadap komunikasi akademis.
\end{abstract}

Kata kunci : Website, Repositori, Skripsi, OAI-PMH, Metadata, Google App Engine.

\section{Latar Belakang}

Repositori umumnya merupakan tempat penyimpanan dan pemeliharaan ratusan data, aplikasi, atau program yang berbentuk format digital untuk didistibusikan secara jaringan komputer dan tersedia yang dapat diakses melalui internet atau dengan media lain seperti dvd yang merupakan alternatif repositori tersebut. Atau sebagai tempat penyimpanan dimana data sebagai arsip server yg bebas digunakan atau didownload, biasanya bersifat open source atau linux. Data-data tersebut disimpan untuk digunakan kembali.

Dalam lingkup civitas perguruan tinggi, repositori sendiri dikenal dengan nama repositori institusi. Repositori institusi memiliki hubungan erat dengan digital library. Repositori ini umumnya dibutuhkan sebagai tempat yang bersifat online untuk mengumpulkan, mengelola, menyebarkan dan melestarikan karya-karya ilmiah yang dihasilkan atau output dari civitas akademik perguruan tinggi tersebut. Pada sebuah institusi atau universitas, karya-karya ilmiah yang dimaksudkan disini umumnya berupa artikelartikel dari jurnal riset, baik sebelum ataupun setelah dicetak, digital format dari skripsi, thesis atau desertasi dan juga mungkin merupakan kumpulan data digital pada kegiatan akademik seperti dokumen administrasi, catatan perkuliahan atau materi perkuliahan lainnya. Hasil dari pada karya-karya ilmiah tersebut akan difungsikan dan dikelola dalam bentuk digital serta dapat dimanfaatkan kembali dalam menunjang kegiatan akademik dan diharapkan dapat menjadi pendukung proses belajar mengajar baik dilingkungan sendiri juga masyarakat luas, baik nasional maupun internasional.

Untuk memudahkan terjadinya pertukaran informasi hasil-hasil karya ilmiah yang telah dihasilkan dibutuhkan suatu sistem harvesting yang terhubung dalam jaringan repositori digital. Sistem harvesting yang akan diimplementasikan adalah sebuah harvester yang menggunakan standar Open Archives Initiative Protocol for Metadata Harvesting (OAI-PMH), yang merupakan teknologi yang bisa digunakan dan diimplementasikan untuk melakukan standarisasi metadata dari koleksi digital.OAI-PMH sendiri di sini digunakan untuk membantu dalam proses penyebaran dan akses metadata yang terdapat didalam web repositori tersebut yang berjalan diatas Google App Engine dan berguna untuk memudahkan availibilitas terhadap komunikasi akademis.

Universitas Mulawarman, sejauh ini belum terdapat wadah untuk menampung semua kumpulan karya ilmiah termasuk dalam hal ini tugas akhir atau skripsi secara online, melainkan hanya dalam bentuk buku yang di kumpulkan di perpustakaan dari fakultas masing-masing. Dengan memanfaatkan aplikasi berbasis website dan 
didukung oleh OAI-PMH yang dibangun menggunakan Platform Google App Engine maka dibuatlah perpustakaan online yang berisi kumpulan skripsi-skripsi mahasiswa.

Website repositori skripsi mahasiswa ilmu komputer ini dapat dibangun untuk memenuhi kebutuhan informasi yang diperlukan mahasiswa mengenai referensi skripsi yang telah dihasilkan oleh angkatan-angkatan sebelumnya di jurusan ilmu komputer. Mahasiswa lain juga dapat menikmati website ini sebagai pengunjung biasa.

\section{PERUMUSAN DAN BATASAN MASALAH}

Berdasarkan uraian tersebut di atas, maka pada penelitian ini dapat dirumuskan permasalahan yang dibahas adalah "Bagaimana merancang bangun sebuah web repositori berbasis OAI-PMH 2.0 menggunakan Platform Google App Engine ?" Sedangkan batasan-batasan masalahnya adalah:

1. Dalam web repositori yang dibangun ini dibatasi hanya berisi kumpulan tugas akhir atau skripsi-skripsi mahasiswa.

2. Web repositori ini di rancang hanya dalam ruang lingkup jurusan Ilmu Komputer Universitas Mulawarman.

3. Fasilitas web repositori terdiri dari halaman utama, halaman repositori skripsi (perpustakaan), pencarian judul dan unduh skripsi.

4. Web repositori ini memiliki dua level login, yaitu sebagai admin, dan anggota.

5. Level login admin memiliki fitur halaman kelola skripsi dan halaman kelola anggota/dosen.

6. Level login anggota memiliki fitur pencarian skripsi dan halaman unduh skripsi.

7. Halaman unduh skripsi bagi anggota terdiri dari bab 1 sampai dengan bab 3 .

8. Halaman unduh skripsi bagi umum hanya berupa artikel atau jurnal.

9. Untuk OAI-PMH yang diterapkan, repositori di sini berperan sebagai Data provider.

\section{TUJUAN DAN MANFAAT}

Tujuan penelitian ini diantaranya untuk:

1. Menyediakan layanan informasi perpustakaan kumpulan skripsi yang bersifat online yang dapat digunakan sebagai salah satu fasilitas untuk memudahkan mahasiswa dalam pencarian referensi skripsi.

2. Menyediakan fitur bagi pengguna dengan level login anggota untuk unduh skripsi secara online. Serta menyediakan fitur pengguna dengan level login admin untuk mengelola skripsi.

3. Mengembangkan suatu Aplikasi Repositori yang dilengkapi dengan kemampuan ekspose metadata melalui OAI-PMH 2.0. Aplikasi ditargetkan untuk berjalan pada platform Google App Engine.
Dengan adanya penelitian ini maka diharapkan dapat memberikan manfaat berupa tersedianya suatu portal publikasi yang dapat memberi kemudahan bagi pengguna web dalam melakukan pencarian referensi skripsi, unduh skripsi serta mempublikasikan skripsi yang kita miliki yang dapat ditelusuri secara online.

Kemudahan yang diberikan juga diikuti dengan fasilitas yang mengutamakan fungsi serta tampilan yang user friendly.

\section{TINJAUAN PUSTAKA Skripsi}

Skripsi adalah karya ilmiah yang ditulis mahasiswa program S-1 yang membahas topik atau bidang tertentu berdasarkan hasil kajian pustaka yang diteliti oleh para ahli, hasil penelitian lapangan atau hasil pengembangan atau eksperimen (Munslich Mansnur, 2009).

Repositori ini merupakan tempat kumpulan skripsi di mana penulis dapat mempublikasikan skripsi yang di hasilkan. Terdapat berbagai macam topik skripsi yang mencakup semua bidang ilmu, Skripsi yang akan ditampilkan merupakan skripsi pada mahasiswa jurusan ilmu komputer Universitas mulawarman. Seperti yang kita ketahui skripsi mahasiswa ilmu komputer umumnya berisi berbagai inovasi di bidang komputer.

\section{Repositori}

Repositori adalah sebuah tempat yang disediakan untuk penyimpanan arsip yang bersifat tetap atau sementara. (Reitz, 2010). Repositori yang digunakan oleh sebuah perguruan tinggi, biasa juga disebut dengan Repositori institusional. Repositori Institusional adalah koleksi digital yang menyediakan dan memberikan akses output intelektual dari sebuah lembaga. (Crow, Pinfield $\mathrm{Tt})$.

\section{OAI-PMH}

OAI-PMH (Open Archives Initiative Protocol for Metadata Harvesting) adalah protokol yang dikembangkan oleh Open Archives Initiative dan digunakan untuk mengkoleksi atau meng-harvest metadata. Metadata yang telah diperoleh, selanjutnya dapat dimanfaatkan sebagai bahan layanan lebih lanjut. Sebagai contoh, protokol OAI digunakan oleh berbagai digital libraries untuk pertukaran metadata (Wikipedia, 2009).

Dalam terminologi pertukaran informasi digital, terdapat 2 kelompok yaitu: data provider dan service provider. Data provider (open archives, repository) menyediakan akses untuk metadata berbagai artikel seperti jurnal dan dokumentasi atau sumber-sumber informasi lainnya. Data provider bertanggung jawab dalam hal penanganan input data serta publikasi informasi dalam suatu repository. Selanjutnya data provider mengubah data menjadi metadata sehingga siap untuk diharvest. Protokol OAI digunakan oleh service provider pada saat melakukan proses harvesting 
serta memasukkan metadata dari data provider. Selanjutnya, service provider menawarkan jasa dalam kerangka harvesting metadata serta memperkaya metadata yang di-harvest untuk dapat bekerja, dengan cara melakukan harvest metadata dari data provider (OAI forum, 2007). Suatu portal publikasi yang dilengkapi dengan fasilitas ekspos metadata tentunya akan meningkatkan penyebaran dan akses secara luas melalui layanan yang disediakan oleh service provider.

Data Provider dapat diakses dan memproses 6 macam OAI-PMH request, yaitu: Identify, Listsets, ListMetaFormats, ListIdentifier, ListRecords, dan GetRecords. Service Provider atau disebut juga harvester, merupakan bagian yang akan mengirim request lalu menerima response berupa metadata yang sesuai dengan request yang diminta dari repository.

OAI-PMH diimplementasikan diatas HTTP dengan respon terhadap permintaan HTTP baik get maupun post. Respon dikembalikan dalam bentuk dokumen XML dengan content type: text/xml dan dikodefikasi dengan menggunakan representasi UTF-8 dari Unicode, jika repositori mendukung set maka informasi set akan di respon dengan baik. Namun respon dapat mengembalikan respon error terkait dengan tidak tersedianya argumen maupun argumen yang diberikan yang tidak sah seperti badVerb, badArgument, noRecordsMatch, cannotDisseminateFormat, badResumptionToken.

\section{Metadata}

Metadata adalah pengindentifikasian, penjelasan suatu data atau diartikan sebagai struktur dari sebuah data (Understanding Metadata, 2009).

Dicontohkan metadata dari katalog buku terdiri dari: judul, pengarang, penerbit, subyek dan sebagainya. Informasi metadata artikel yang diambil dari repositori mengikuti standar metadata OAI Dublin Core, yang merupakan standard penulisan metadata paling banyak digunakan di dunia dan dikenal sebagai bahasa sederhana untuk menjelaskan sebuah resources. Dublin core terdiri dari 15 elemen utama, yang dapat dikembangkan sesuai kebutuhan organisasi. Elemen ini adalah :

Title, Creator, Description, Subject, Publisher, Contributor, Date, Type, Format, Identifier, Source, Language, Relation, Coverage, dan Rights.

\section{Google App Engine}

Google App Engine merupakan sebuah Paas (Platform as a Service) yang menawarkan dan memungkinkan kita untuk membangun dan menjalankan aplikasi pada infrastruktur google. Aplikasi App Engine mudah digunakan untuk membangun, memelihara aplikasi, dan untuk penyimpanan data. (Google Cloud Platform, 2010). Google App Engine mendukung aplikasi yang ditulis dalam berbagai bahasa pemrograman. Diantaranya Java, Python, PHP dan Go. Dalam proses membangun website digunakan Google App
Engine Launcher dan Google Cloud Storage sebagai penyimpanan data di google.

\section{METODOLOGI PENELITIAN}

Waktu dan tempat Penelitian

Penelitian dilakukan dalam waktu kurang lebih 9 bulan dimulai dari bulan Mei sampai dengan bulan Februari 2015. Penelitian dilaksanakan di Laboratorium RPL FMIPA dan Kampus Gunung Kelua Universitas Mulawarman.

\section{Metode Pengembangan Sistem}

Dalam pengembangan sistem ini penulis menggunakan metode waterfall. Metode waterfall sendiri merupakan metode yang paling sering digunakan pada umumnya. Inti dari metode waterfall adalah pengerjaan dari suatu sistem dilakukan secara berurutan atau secara linear. Jadi jika langkah ke-1 belum dikerjakan, maka langkah 2 tidak dapat dikerjakan. Jika langkah ke-2 belum dikerjakan maka langkah ke-3 juga tidak dapat dikerjakan, begitu seterusnya. Secara otomatis langkah ke-3 akan bisa dilakukan jika langkah ke-1 dan ke-2 sudah dilakukan. Secara garis besar metode waterfall mempunyai langkah-langkah Analisa, Desain, Penulisan, Pengujian dan Penerapan serta Pemeliharaan. (Kadir, 2003).

\section{Tahap Pengembangan Sistem}

Tahapan - tahapan yang terjadi dalam pengembangan sistem penulis telah membuat gambaran singkat seperti berikut :

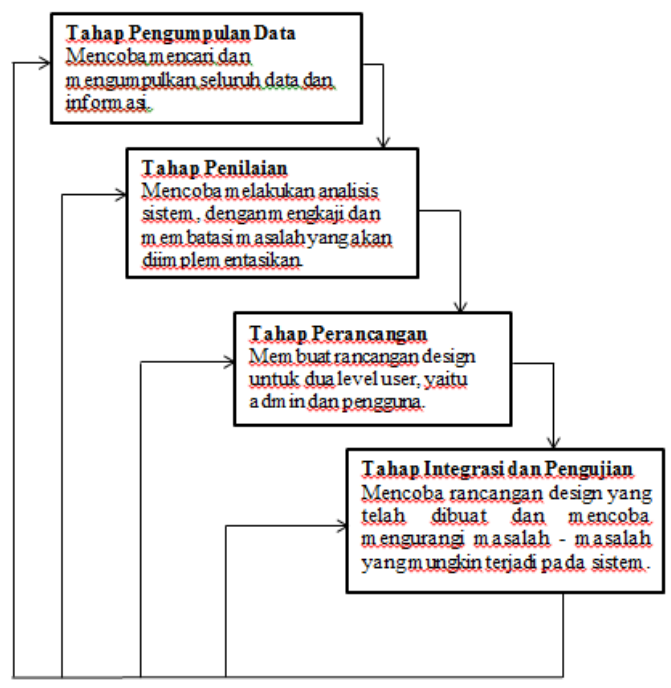

Gambar 1 Tahapan - Tahapan yang terjadi dalam Pengembangan Sistem

Menyesuaikan dari gambaran di atas, tahapan pengembangan dalam sistem ini dapat dijelaskan seperti berikut :

1. Tahap Pengumpulan Data

Tahap pengumpulan data adalah cara yang dilakukan dengan mencari sumber informasi, menyusun dan menjelaskan secara sistematis mengenai data yang diperlukan dalam sebuah laporan. Dalam pengumpulan data ini penulis 
menggunakan berbagai macam studi literature yaitu seperti mencari dan membaca referensi yang berupa buku, literatur, jurnal dan web yang berkaitan dengan HTML, PHP, CSS, Java Script, UML, desain website, basis data, metode OAI-PMH dan mengenai Platform Google App Engine yang tentunya berkenaan serta menunjang penelitian.

2. Tahap Penilaian

Tahap ini merupakan tahap penentuan hal-hal penting sebagai dasar permasalahan yang akan di analisis. Tahap ini merupakan tahap untuk mengkaji dan membatasi masalah yang akan diimplementasikan dalam sistem seperti:

1. Deskripsi dan tujuan perancangan.

2. Kebutuhan fungsional web repositori skripsi.

3. Kebutuhan pengguna aplikasi baik anggota maupun administrator.

3. Tahap Perancangan

Proses rancang bangun sistem serta menulis spesifikasi desain yang detail dan menyusun rencana-rencana implementasi, seperti :

1. Gambaran awal aplikasi.

2. Pemodelan sistem.

3. Perancangan antar muka halaman aplikasi.

4. Perancangan basis data.

4. Tahap Integrasi dan Pengujian

Tahap integrasi adalah proses penerapan OAIPMH 2.0 ke halaman web yang telah di buat secara keseluruhan. Setelah melewati tahap integrasi akan dilanjutkan ke tahap pengujian aplikasi secara menyeluruh sehingga apabila terdapat kesalahan dapat dilakukan perbaikan.

Tahap pengujian ini diperlukan untuk memastikan bahwa aplikasi yang telah di buat sudah benar dan sesuai dengan karakteristik yang telah ditetapkan.

\section{Analisis Kebutuhan Sistem}

1. Kebutuhan Perangkat Keras (Hardware)

Untuk pengerjaan tugas akhir ini penulis menggunakan laptop dengan spesifikasi Processor Intel(R) Core(TM) i5 $2.4 \mathrm{GHz}$, RAM DDR3 4 GB, Harddisk dengan kapasitas 550 GB.

2. Kebutuhan Perangkat Lunak (Software) Perangkat lunak yang digunakan pada penelitian ini adalah sebagai berikut: Windows 7, XAMPP, Sublime dan browser for windows.

\section{HASIL DAN PEMBAHASAN \\ Deskripsi Aplikasi}

Aplikasi yang dirancang merupakan sebuah web repositori skripsi mahasiswa ilmu komputer berbasis OAI-PMH 2.0 dengan menggunakan Google App Engine. Aplikasi dirancang dengan tujuan mempermudah proses manajemem web repositori diantaranya mengumpulkan, menyimpan dan mempublikasikan skripsi-skripsi mahasiswa ilmu komputer Fakultas MIPA Universitas Mulawarman. Pengguna utama aplikasi adalah pihak admin web repository, pihak anggota dan pihak umum sebagai user.

Analisis Kebutuhan Fungsional

1. Kebutuhan Fungsional Halaman Utama

a. Login user

b. Form pencarian umum

c. Unduh skripsi hanya berupa jurnal

2. Kebutuhan Fungsional Halaman Anggota

a. Form pencarian

b. Form ubah password

c. Unduh skripsi dari abstrak, cover, jurnal, bab 1 hingga bab 3.

3. Kebutuhan Fungsional Halaman Admin

a. Login Admin

b. Input dan lihat data umum, data admin, data anggota, data dosen, data fakultas, data program studi, dan data jurusan.

c. Buka, edit dan menghapus data umum, data admin, data anggota, data dosen, data fakultas, data program studi, dan data jurusan.

Dari hasil analisis akan dilanjutkan dengan pembuatan coding dan tahap berikutnya adalah penggabungan desain halaman aplikasi serta fungsi dan penerapan metode OAI-PMH 2.0 ke halaman web yang telah dibuat.

\section{Perancangan Sistem}

Pada dasarnya untuk pembuatan aplikasi rancang bangun web repositori skripsi mahasiswa ini, membutuhkan perangkat keras dan perangkat lunak. Perangkat keras yang digunakan yaitu berupa komputer dan perangkat lunak yang digunakan yakni program untuk membuat tampilan interface. Serta program untuk database yang mendukung dalam pembuatan web ini. Dan juga data file skripsi yang akan digunakan oleh OAIPMH 2.0 untuk meng-expose metadata yang tersedia dari file-file skripsi tersebut.

Pada pemodelan sistem disini penulis membuat skenario sistem dalam bentuk diagram DFD dan ERD. Dari gambar di bawah dapat dijelaskan bahwa pada gambar terdapat 3 Aktor yaitu Admin, Anggota dan user umum. Admin dan anggota yang terdaftar harus login dahulu ke dalam repositori dengan menggunakan username dan password agar selanjutnya dapat menjalankan fungsi masing-masing. Admin yang berhasil login bertugas mengelola semua data yang ada di dalam repositori, sedangkan anggota dan user umum dapat melakukan pencarian dan mengunduh data dan file skripsi sesuai batasan yang tersedia.

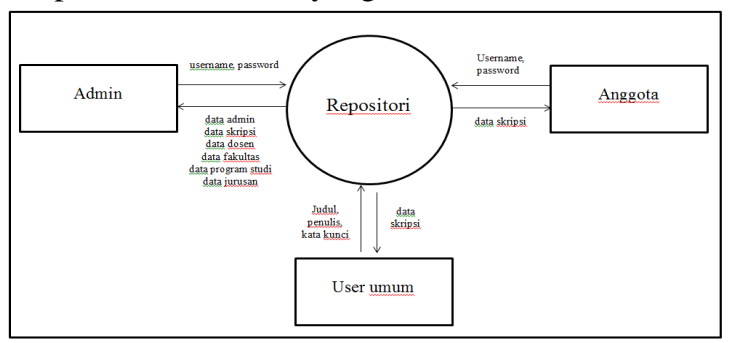

Gambar 2. DFD level 0 repositori 
Pada gambar 3 terdapat DFD level 1 admin, yatu penjelasan mengenai arus data atau keluarmasuknya aliran data yang terjadi antara admin dan sistem repositori.

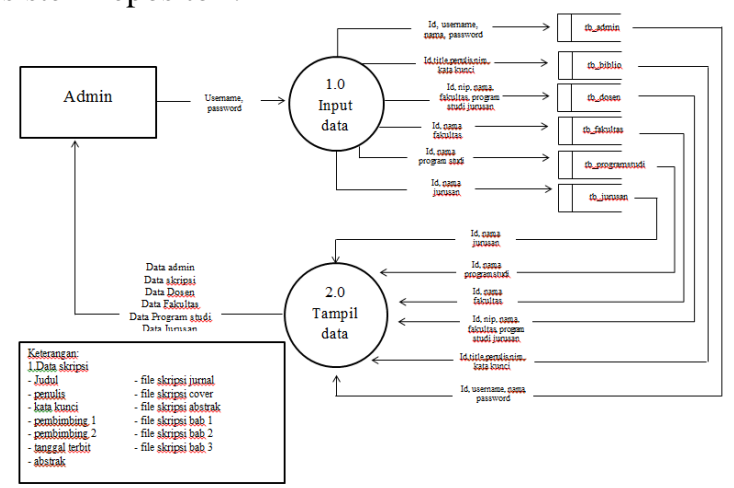

Gambar 3. DFD level 1 repositori admin

Pada gambar 4 dijelaskan mengenai arus data atau keluar-masuknya aliran data yang terjadi antara anggota yang terdaftar dan sistem repositori.

Sedangkan pada gambar 5 dijelaskan mengenai user umum dan repository.

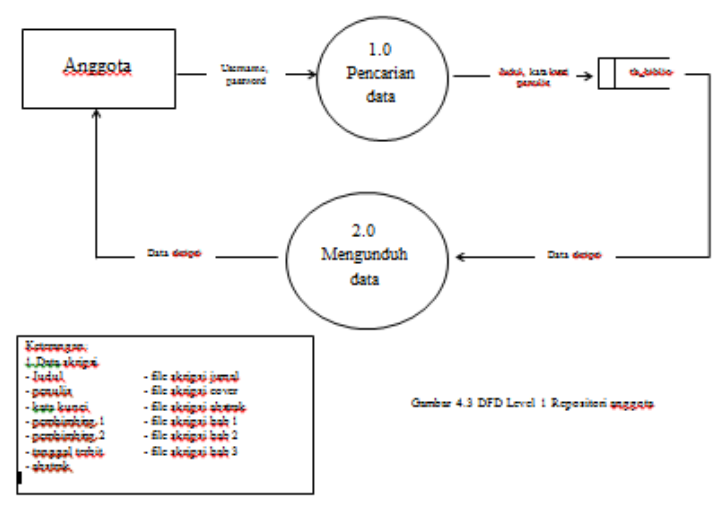

Gambar 4 DFD level 1 repositori anggota

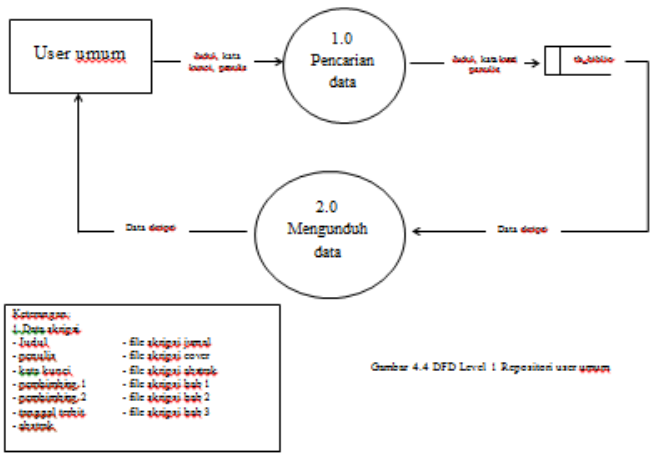

Gambar 5 DFD level 1 repositori user umum

Pada gambar 6 dibawah ini menjelaskan ERD yang terjadi antar table repositori.

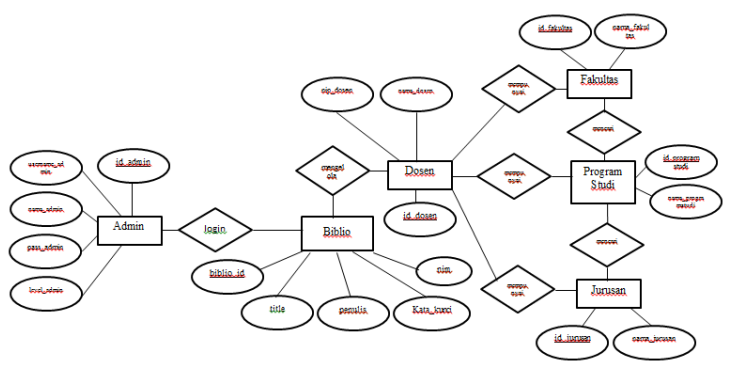

Gambar 6 ERD repositori

Pada tahap perancangan basis data terdapat 1 database yang terdiri dari 11 tabel yaitu:

1. tabel biblio

tabel 1 digunakan admin untuk menyimpan data dan file skripsi mahasiswa/i. Tabel ini juga yang membantu OAI-PMH 2.0 untuk mengharvest metadata dari setiap record data skripsi yang telah disimpan.

Tabel 1 tabel biblio

\begin{tabular}{|l|l|l|}
\hline No & \multicolumn{1}{|c|}{ Nama Field } & Type Data \\
\hline 1. & biblio_id & Int (11) \\
\hline 2. & title & Text \\
\hline 3. & penulis & Varchar (100) \\
\hline 4. & nim & Varchar (30) \\
\hline 5. & publisher_id & Int (11) \\
\hline 6. & kata_kunci & Varchar (100) \\
\hline 7. & pembimbing_um & Varchar (200) \\
& um & \\
\hline 8. & pembimbing2_u & Varchar (200) \\
& mum & \\
\hline 9. & tanggal_terbit & Varchar (10) \\
\hline 10. & language_id & Char (5) \\
\hline 11. & type_id & Varchar (100) \\
\hline 12. & datestamp & Date \\
\hline 13. & abstrak_detail & text \\
\hline 14. & id_fakultas & Int (5) \\
\hline 15. & id_programstudi & Int (5) \\
\hline 16. & id_jurusan & Int (5) \\
\hline 17. & cover_umum & Varchar (50) \\
\hline 18. & abstrak_umum & Varchar (50) \\
\hline 19. & jurnal_umum & Varchar (50) \\
\hline 20. & bab_1_umum & Varchar (50) \\
\hline 21. & bab_2_umum & Varchar (50) \\
\hline 22. & bab_3_umum & Varchar (50) \\
\hline & \multicolumn{2}{|l}{} \\
\end{tabular}

2. tabel tb_admin

Tabel 2 adalah tb admin yang digunakan untuk mengakses ke dalam website repositori skripsi ilkom universitas mulawarman, di tabel ini Admin dan anggota repositori dapat dibedakan melalui level yang di inputkan, admin dengan level 1 dan anggota dengan level 2. 
Tabel 2 tabel tb admin

\begin{tabular}{|l|l|l|}
\hline No & \multicolumn{1}{|c|}{ Nama Field } & \multicolumn{1}{|c|}{ Type Data } \\
\hline 1. & id_admin & $\operatorname{Int}(5)$ \\
\hline 2. & username_admin & Varchar(20) \\
\hline 3. & nama_admin & Varchar(50) \\
\hline 4. & pass_admin & Varchar(40) \\
\hline 5. & level_admin & $\operatorname{Int}(1)$ \\
\hline
\end{tabular}

3. tabel tb_dosen

Tabel 3 adalah tb_dosen yang digunakan untuk menyimpan data-data dosen sebagai pembimbing dan kontributor dari skripsiskripsi yang dihasilkan

Tabel 3 tabel tb_dosen

\begin{tabular}{|l|l|l|}
\hline No & \multicolumn{1}{|c|}{ Nama Field } & \multicolumn{1}{|c|}{ Type Data } \\
\hline 1. & id_dosen & $\operatorname{Int}(5)$ \\
\hline 2. & nip_dosen & Varchar(30) \\
\hline 3. & nama_dosen & Varchar(50) \\
\hline 4. & fakultas_dosen & $\operatorname{Int}(5)$ \\
\hline 5. & jurusan_dosen & $\operatorname{Int}(5)$ \\
\hline 6. & programstudi_dosen & $\operatorname{Int}(5)$ \\
\hline
\end{tabular}

4. tabel tb_fakultas

Tabel $\overline{4}$ adalah Tabel tb_fakultas berisikan mengenai daftar nama fakultas, yang menunjukan dari fakultas mana dosen yang membimbing dan mahasiswa/i yang menghasilkan skripsi berasal.

Tabel 4 tabel tb_fakultas

\begin{tabular}{|c|l|l|}
\hline No & \multicolumn{1}{|c|}{ Nama Field } & Type Data \\
\hline 1. & id_fakultas & $\operatorname{Int}(5)$ \\
\hline 2. & nama_fakultas & $\operatorname{Varchar}(50)$ \\
\hline
\end{tabular}

5. tabel tb_programstudi

Tabel 5 terdiri dari 3 field. Yaitu id_proram studi fakultas_programstudi dan nama_program studi. Tabel ini digunakan untuk menyimpan data program studi dari dosen dan mahasiswa/i yang bersangkutan.

Tabel 5 tabel tb_programstudi

\begin{tabular}{|l|l|l|}
\hline No & \multicolumn{1}{|c|}{ Nama Field } & Type Data \\
\hline 1 & id_programstudi & $\operatorname{Int}(5)$ \\
\hline 2. & fakultas_progamstudi & $\operatorname{Int}(5)$ \\
\hline 3. & nama_programstudi & Varchar(50) \\
\hline
\end{tabular}

6. table tb_jurusan

Tabel 6 adalah tb_jurusan Tabel ini digunakan untuk menyimpan data jurusan dari dosen dan mahasiswa/i yang bersangkutan.

Tabel 6 tabel tb_jurusan

\begin{tabular}{|l|l|l|}
\hline No & \multicolumn{1}{|c|}{ Nama Field } & \multicolumn{1}{c|}{ Type Data } \\
\hline 1. & id_jurusan & $\operatorname{Int}(5)$ \\
\hline 2. & fakultas_jurusan & $\operatorname{Int}(5)$ \\
\hline 3. & programstudi_jurusan & $\operatorname{Int}(5)$ \\
\hline 4. & nama_jurusan & Varchar(50) \\
\hline
\end{tabular}

7. Tabel biblio_topic

Tabel 7 terdiri dari 2 field. yaitu biblio_id dan topic_id. Tabel ini digunakan oleh OAI-PMH 2.0 untuk mengharvest topik dari masingmasing skripsi mahasiswa/i, yang akan tampil dalam request verb $=$ "ListSets", dan output sebagai <SetSpec>.

Tabel 7 tabel biblio_topic

\begin{tabular}{|l|l|l|}
\hline No & \multicolumn{1}{|c|}{ Nama Field } & \multicolumn{1}{|c|}{ Type Data } \\
\hline 1. & biblio_id & $\operatorname{Int}(11)$ \\
\hline 2. & topic_id & $\operatorname{Int}(11)$ \\
\hline
\end{tabular}

8. Tabel mst_topic

Tabel mst_topic terdiri dari empat field, yaitu topic_id, topic, input_date dan last_update. Tabel mst_topic merupakan isi topik dari tabel biblio_topic yang saling berelasi. Tempat dimana mengambil topik-topik skripsi yang dihasilkan oleh mahasiswa/i dan yang tentunya akan digunakan oleh OAI-PMH 2.0.

Tabel 8 tabel mst_topic

\begin{tabular}{|l|l|l|}
\hline No & \multicolumn{1}{|l|}{ Nama Field } & \multicolumn{1}{|c|}{ Type Data } \\
\hline 1. & topic_id & $\operatorname{Int}(11)$ \\
\hline 2. & Topic & Varchar(50) \\
\hline 3. & input_date & Date \\
\hline 4. & last_update & Date \\
\hline
\end{tabular}

9. Tabel mst_publisher

Tabel mst_publisher terdiri dari empat field, yaitu publisher_id, publisher_name, input_date dan last_update. Tabel ini digunakan oleh tabel biblio untuk mengambil publisher (penerbit) skripsi yang bersangkutan, Tabel ini juga yang berperan dalam OAI-PMH 2.0 untuk mengharvest publisher dari masing-masing skripsi mahasiswa/i, dengan output sebagai <dc:publisher> dalam bentuk metadata Dublin core. Dikarenakan semua skripsi yang ada merupakan terbitan dari Repository Ilkom Unmul, maka semua publisher berisi sama.

Tabel 9 tabel mst_publisher

\begin{tabular}{|c|l|l|}
\hline No & \multicolumn{1}{|c|}{ Nama Field } & \multicolumn{1}{|c|}{ Type Data } \\
\hline 1. & publisher_id & Int $(11)$ \\
\hline 2. & publisher_name & Varchar(100) \\
\hline 3. & input_date & Date \\
\hline 4. & last_update & Date \\
\hline
\end{tabular}

10. Tabel mst_type

Tabel mst_type terdiri dari empat field, yaitu type_id, type_name, input_date dan last_update. Tabel ini digunakan oleh tabel biblio untuk mengambil tipe id dari record masing-masing skripsi yang bersangkutan, Tabel ini juga yang berperan dalam OAI-PMH 2.0 untuk mengharvest type record dari masing-masing skripsi mahasiswa/i, yang akan tampil dalam request verb= "ListRecord" dan request verb="GetRecord", dengan output 
sebagai <dc:type> dalam bentuk metadata Dublin core. Dikarenakan semua record yang ada merupakan skripsi atau tugas akhir mahasiswa/i, maka semua tipe berisi sama, yaitu sebagai Student papers.

Tabel 10 tabel mst_type

\begin{tabular}{|l|l|l|}
\hline No & Nama Field & \multicolumn{1}{|c|}{ Type Data } \\
\hline 1. & type_id & $\operatorname{Int}(11)$ \\
\hline 2. & type_name & Varchar(100) \\
\hline 3. & input_date & Date \\
\hline 4. & last_update & Date \\
\hline
\end{tabular}

11. Tabel mst_language

Tabel mst_language terdiri dari empat field, yaitu_language_id, language_name, input_date dan last_update. Tabel ini digunakan oleh tabel biblio untuk mengambil language id atau bahasa yang digunakan dari masing-masing skripsi yang bersangkutan, begitu juga halnya dengan OAI-PMH 2.0 yang menggunakan tabel ini untuk mengharvest bahasa yang digunakan, yang akan tampil dalam request verb="ListRecord" dan request verb="GetRecord", dengan output sebagai <dc:language> dalam bentuk metadata Dublin core.

Tabel 11 tabel mst_language

\begin{tabular}{|l|l|l|}
\hline No & \multicolumn{1}{|c|}{ Nama Field } & \multicolumn{1}{|c|}{ Type Data } \\
\hline 1. & language_id & Char(5) \\
\hline 2. & language_name & Varchar(20) \\
\hline 3. & input_date & date \\
\hline 4. & last_update & Date \\
\hline
\end{tabular}

\section{IMPLEMENTASI SISTEM}

Implementasi sistem merupakan proses realisasi sistem yang dilakukan berdasarkan pada desain atau rancangan aplikasi yang telah dibuat diawal. Pada aplikasi ini terdapat 3 user yang bisa mengakses repositori ini yaitu: user umum, anggota dan admin. Apabila aplikasi ini dieksekusi, dihttp://repositoryskripsiilkomunmul.appspot.com/. maka akan muncul halaman utama yang bisa diakses oleh semua user, seperti pada gambar 7 .

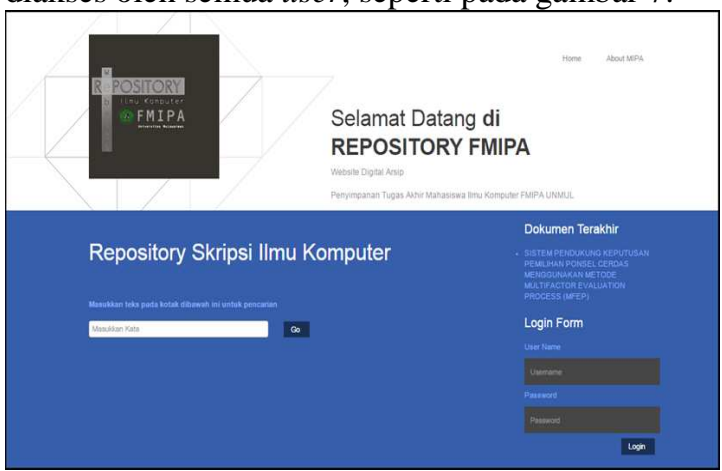

Gambar 7 Tampilan Halaman Utama Website

Gambar 7 merupakan halaman utama website. Bagi anggota dan admin dapat melakukan proses login di login form yang tersedia. Pada halaman ini semua user dapat melakukan pencarian di form pencarian, dan ketika mengklik go maka halaman hasil pencarian pada gambar 8 akan muncul.

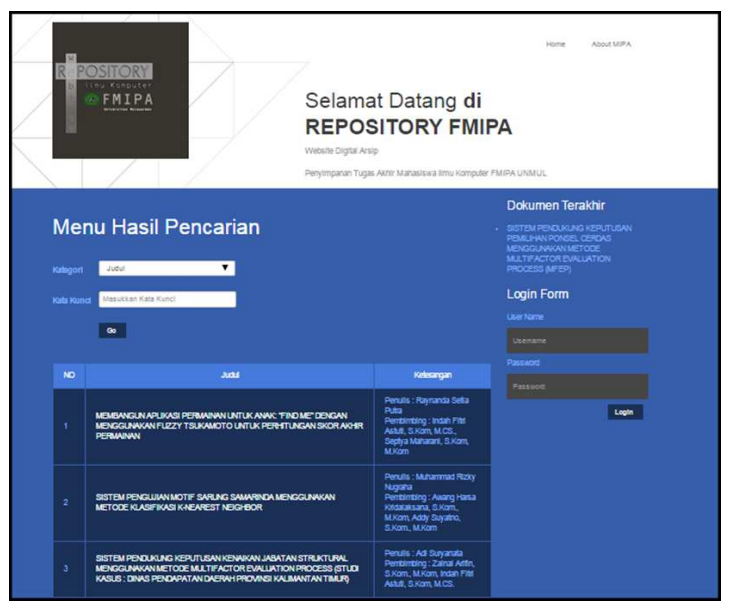

Gambar 8 Tampilan Halaman hasil pencarian

Pada gambar 8 terdapat list hasil pencarian data file skripsi. Jika user mengklik pada judul maka data file skripsi akan muncul, dan user dapat mengunduh file skripsi yang tersedia. Pada user umum file skripsi yang dapat diunduh hanya berupa jurnal, sedangkan untuk anggota dapat mengunduh semua file; jurnal, cover, abstrak, bab 1 hingga bab 3 .

Gambar 9 menampilkan halaman admin, admin yang berhasil login, akan masuk ke halaman ini. Halaman ini digunakan admin untuk mengelola aplikasi website repositori skripsi ilkom unmul. Mulai dari melihat, menginput, mengedit, hingga menghapus data yang ada, seperti data skripsi, data admin, data anggota, data dosen, data fakultas, data program studi dan data jurusan yang terdaftar.

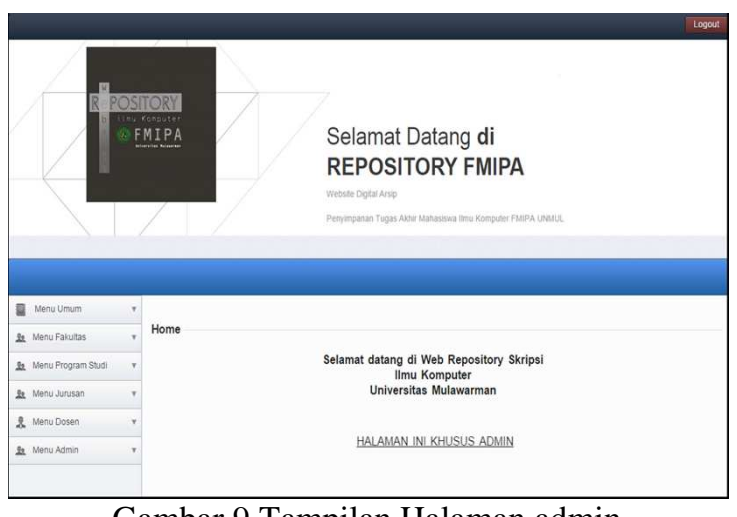

Gambar 9 Tampilan Halaman admin

\section{Halaman OAI-PMH 2.0}

Dalam mengharvest metadata, OAI-PMH 2.0 menggunakan data-data yang ada di repositori sebagai pendukungnya. OAI-PMH 2.0 yang dikenal sebagai Open archives Initiative for metadata harvesting ini menggunakan metadata yang tersedia untuk dapat digunakan dalam berbagai pertukaran metadata di berbagai digital libraries. Dalam hal ini repositori skripsi ilmu komputer universitas mulawarman berperan sebagai data provider yang bertanggung jawab dalam hal penanganan input 
data serta publikasi informasi dalam suatu repositori. Data provider sendiri dapat memproses 6 (enam) macam request OAI-PMH, yaitu Identify, List metadataformats, List sets, List Identifier, List record dan Get record. Repositori ini juga telah melewati tahap validasi data provider di www.openarchives.org/Register/ValidateSite yang dapat dilihat pada gambar dibawah ini

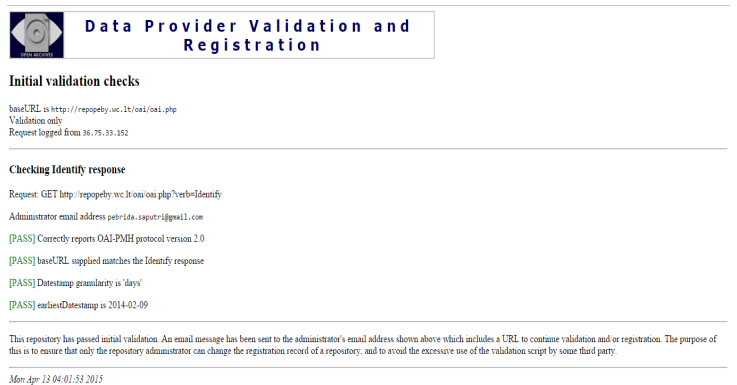

Gambar 10 Hasil Validasi Repositori

\section{Identify}

Identify digunakan untuk mengambil informasi mengenai sebuah repositori seperti administrator dan lain-lain, ketika mengirim request verb $=$ Identify maka akan mendapat response seperti pada potongan gambar 11

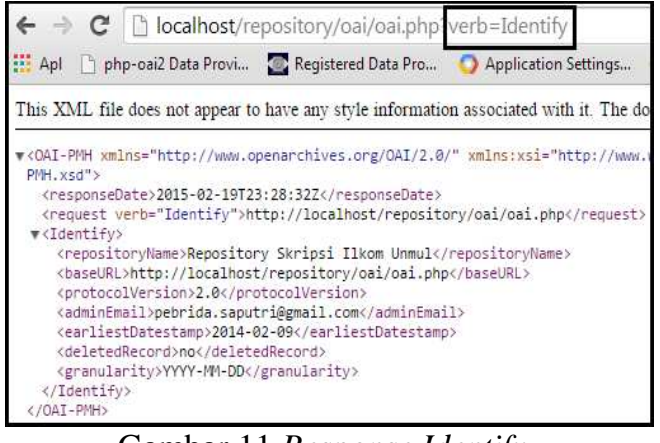

Gambar 11 Response Identify

\section{List Metadataformats}

List Metadataformats digunakan untuk mengambil format metadata yang tersedia pada sebuah repositori. Dikarenakan pada repositori ilkom unmul ini menggunakan metadata Dublin core, maka metadatanya berisi "oai_dc". Ketika mengirim request verb = ListMetadataformats, maka response dapat dilihat seperti pada potongan gambar 12

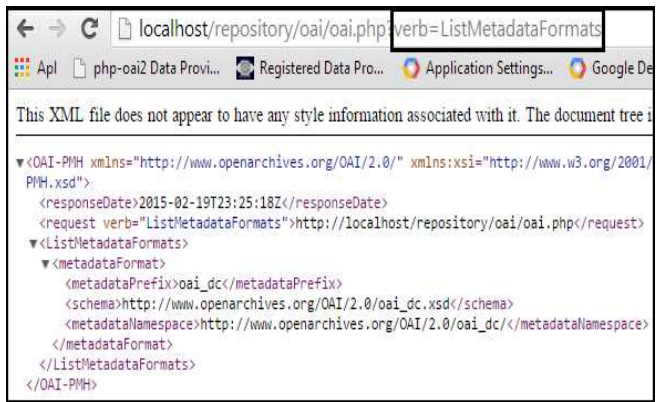

Gambar 12 Response ListMetadataFormats

\section{List Sets}

List Sets, digunakan untuk mengambil struktur set dari sebuah repositori. Informasi ini sangat berharga untuk pengumpulan jenis metadata tertentu. Dalam hal ini set atau topik yang ada di dalam repositori ini hanya berisi satu, yaitu komputer, karena semua skripsi bertema atau bertopik komputer. Response yang di dapat, ketika mengirim request verb $=$ ListSets, dapat dilihat pada gambar 13

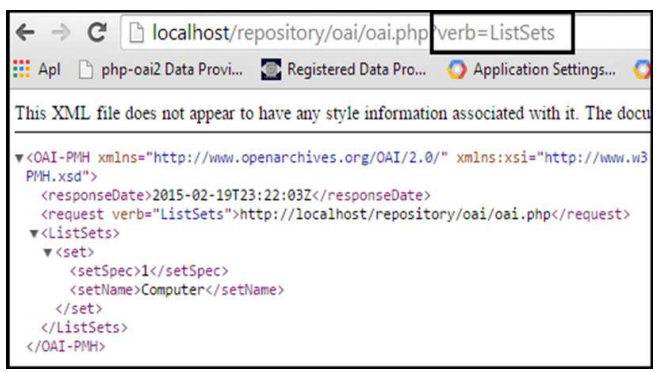

Gambar 13 Response ListSets

\section{List Identifiers}

List Identifiers, merupakan permintaan yang hanya mengambil informasi mengenai Identifier, datestamp dan set. Response yang akan di dapat ketika mengirim request verb $=$ ListIdentifiers dapat dilihat pada potongan gambar 14

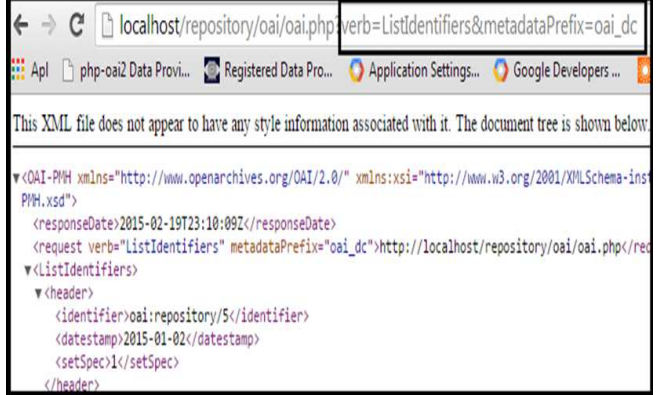

Gambar 14 Response ListIdentifiers

\section{List Records}

List Record, digunakan untuk mengumpulkan record dari sebuah repositori. Record berisi metadata-metadata yang terkumpul, dan di ambil dari data-data yang telah di inputkan di dalam sebuah repositori. Ketika mengirim request verb = ListRecords, maka akan mendapat response seperti pada potongan gambar 15

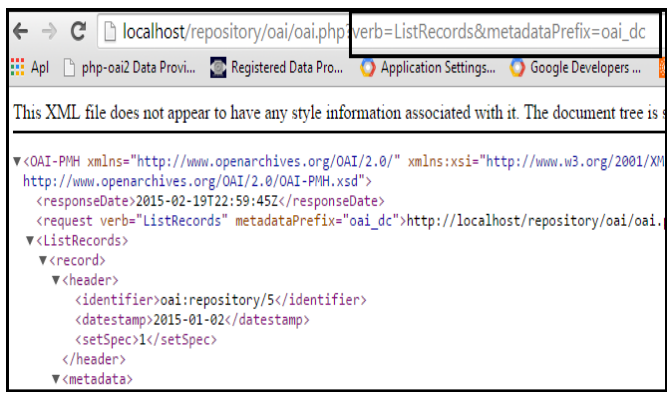

Gambar 15 Response ListRecords 


\section{Get Record}

Get Record digunakan untuk mengambil sebuah record tertentu dari sebuah repositori. Dibutuhkan argument yang menjelaskan bahwa Identifier sebuah item berasal dari record yang diminta dan metadata format dari metadata harus disertakan pada record. Ketika mengirim request verb $=$ GetRecord, maka akan mendapat response seperti pada potongan gambar 16

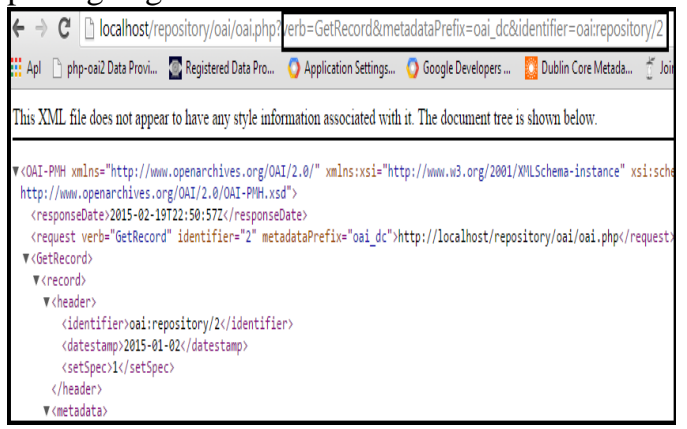

Gambar 13 Response GetRecords

\section{KESIMPULAN DAN SARAN}

Berdasarkan penelitian yang telah dilakukan oleh penulis, dapat diperoleh beberapa kesimpulan, diantaranya:

1. Aplikasi website repository skripsi ilmu komputer universitas mulawarman berfungsi sebagai digital library, dapat digunakan sebagai salah satu fasilitas untuk memudahkan mahasiswa dalam pencarian referensi skripsi.

2. Aplikasi website repository skripsi ilmu komputer universitas mulawarman, dilengkapi dengan fasilitas pencarian skripsi dan unduh skripsi secara online. Untuk anggota, skripsi dapat diunduh dari jurnal hingga bab 3 sedangkan untuk non anggota skripsi hanya dapat diunduh berupa jurnal saja.

3. Membangun website repository berbasis OAIPMH 2.0 dapat memudahkan service provider untuk mengharvest metadata dari data-data yang ada.

4. Platform Google App Engine yang menggunakan bahasa PHP, masih terdapat banyak keterbatasan, diperkirakan karena bahasa PHP yang masih berstatus beta dan platform bersifat gratis.

5. Repositori skripsi ilmu komputer universitas mulawarman ini telah melewati tahap validasi data provider di www.openarchives.org/Register/ValidateSite yang dapat dilihat pada gambar 10.

Beberapa saran yang berguna dalam pengembangan sistem selanjutnya antara lain :

1. Pengembangan aplikasi selanjutnya diharapkan dapat diimplementasikan menggunakan mobile ataupun android.

2. OAI-PMH 2.0 yang digunakan bisa dikembangkan tidak hanya sebagai data provider tapi juga dapat daftarkan di service provider.

\section{DAFTAR PUSTAKA}

[1]. Archives, Open. Open Archives Initiative Protocol for Metadata Harvesting. Open Archive.Tersedia:www.openarchives.org[09 Mei 2014].

[2]. Cloud Platform, Google. Google Cloud Platform for PHP Introduction. Google Cloud Platform.Tersedia:

https://cloud.google.com/appengine/docs/php/ gettingstarted/introduction[02 April 2014].

[3]. Community, The Metadata. 2012. Dublin Core Metada Element Set Version 1.1. Metadata Dublin Core®Metadata Intiative Innovation.Tersedia:www.dublincore.org[14 Desember 2014].

[4]. Digital, Minnesota. 2006. Dublin Core Metadata Best Practices. CDP Metadata Working Group. Tersedia:www.mndigital.org/digitizing/../meta data.pdf [11 February 2015]

[5]. Fahmi, Ismail. 2003. Inovasi Jaringan Perpustakaan Digital Network of Network (NeONs). Knowledge Management Research Group Institut Tekhnologi Bandung.Tersedia:directory.umm.ac.id/.../indo nesia/education/idln-neon-paper-2003.pdf [26 April 2014].

[6]. Government, OSTI. 2007. OSTI OAI Repository Manual. Osti Government. Tersedia:www.osti.gov/OSTI_OAIrepository manual.pdf [21 Juni 2014].

[7]. Hendra \& Jimmy. 2013. Repositori Publikasi Berbasis OAI-PMH 2.0 dengan Google App Engine. STMIK IBBI Medan. Tersedia: jurnalcoreit.lppmstmik.ibbi.ac.id/permalink/000012.pdf April 2014].

[8]. National, Australian Data Service. 2010. OAIPMH Metadata Harvesting - Australian National Data Service. Australian National Data Service. Tersedia: www.ands.org.au/guides/dcb/shen-oaipmh.pdf [28 Juni 2014].

[9]. Peranginangin, Kasiman. 2006. Apliksi WEB dengan PHP dan MySQL. Yogyakarta: C.V. ANDI OFFSET.

[10]. Pranata, Dana. 2013. Rancang Bangun Website Jurnal Ilmiah Bidang Komputer (Studi Kasus Program Studi Ilmu Komputer) Universitas Mulawarman. Samarinda: Fakultas Matematika dan Ilmu pengetahuan Alam Universitas Mulawarman.

[11]. Putro, H.I., Lim, R, \& Dillak, R.Y. 2009. Aplikasi Web Direktori Jurnal Menggunakan Feature Harvester Metadata Artikel. Posiding SENTIA 2009-Politeknik Negeri Malang. Tersedia: http://fportfolio petra.ac.id/user_files/03002/Paper\%20for\%20SENTIA\%2009.pdf [08 April 2014]. 